\title{
Softening Behavior During Annealing of Overaged and Cold-rolled Aluminum Alloy 7075
}

\author{
Saul Hissaci de Souza ${ }^{*} \mathbb{D}^{\circ}$, Angelo Fernando Padilha ${ }^{b}$, Andrea Madeira Kliauga \\ ${ }^{a}$ Escola Politécnica, Universidade de São Paulo, São Paulo, SP, Brasil \\ ${ }^{b}$ Departamento de Engenharia Metalúrgica e de Materiais, Escola Politécnica, Universidade de São \\ Paulo, São Paulo, SP, Brasil \\ ${ }^{c}$ Departamento de Engenharia de Materiais - DEMA, Universidade Federal de São Carlos, São Carlos, \\ SP, Brasil
}

Received: October 10, 2018; Revised: April 02, 2019; Accepted: April 08, 2019

This work proposes studying the softening kinetics of aluminum alloy 7075-T6. Firstly, AA 7075 strips were overaged $\left(300^{\circ} \mathrm{C}\right.$ and 5 hours). Then, the overaged strips were cold-rolled at room temperature $\left(45 \%\right.$ in thickness reduction) and, after that, annealed at different temperatures $\left(200^{\circ} \mathrm{C}\right.$ and $250^{\circ} \mathrm{C}$ ) and time intervals (30 minutes -4 hours). By using polarized light microscopy, EBSD and Vickers hardness measurements, the softening mechanisms were determined and proper mathematical models (Kuhlmann, Johnson-Mehl-Avrami-Kolmogorov and Austin-Rickett) were used to analyse the experimental data. The results show that although almost all observed softening can be attributed to recovery, the phenomena is well described by using mathematical models for phase transformations (JMAK and Austin Riccket). In order to promote recrystallization of overaged AA 7075, an additional thickness reduction $(75 \%)$ were used. These samples were annealed isocronically during 1 hour $\left(100-400^{\circ} \mathrm{C}\right)$ and it was found that recrystallization only took place at $400^{\circ} \mathrm{C}$.

Keywords: Aluminum alloy 7075, annealing, cold-rolling, recovery, recrystallization.

\section{Introduction}

The 7000 series of commercial aluminum alloys are widely used in structures that require a high strength/weight ratio, like aircrafts structures. These alloys undergo thermomechanical treatments that provide a microstructure with fine, coherent and/or semi-coherent, and well distributed $\mathrm{MgZn}_{2}$ precipitates, which are the mainly responsible for alloy's high strength (Yield stress $\approx 500 \mathrm{MPa}$ ). Although the 7075 aluminum alloy has high mechanical strength, its low toughness and stress-corrosion susceptibility might be a problem for some applications. Therefore, new thermomechanical cycles have been developed to overcome these difficulties ${ }^{1,2}$.

The grain refining provided by recrystallization is desirable for most metallic materials, since it leads to an increase in both mechanical strength and toughness ${ }^{3}$. Therefore, the knowledge about AA 7075 recrystallization kinetics under different conditions is useful to reach desired microstructures and properties.

In the present study, the softening behavior of AA 7075 - T6 (Al - Zn - Mg - Cu) was investigated after overaging $\left(300^{\circ} \mathrm{C}-5\right.$ hours), cold-rolling $(45 \%$ and $75 \%)$, and subsequent annealing.

*e-mail: saulhso@usp.b

\section{Material and Experimental Procedure}

All the samples used in this work were obtained from a $10 \mathrm{~mm}$ thick rolled plate of AA 7075 - T6 alloy. The alloy's chemical composition is presented in Table 1.

The experimental procedure can be summarized in three main steps: a) As received AA 7075 (T6) was initially characterized by using polarized light microscopy (PLM), scanning electron microscopy (SEM), energy dispersive spectroscopy (EDS), X-ray diffraction (XRD), transmission electron microscopy (TEM) and Vickers hardness test (HV 0.3 ); b) The AA 7075 (T6) was overaged at $300^{\circ} \mathrm{C}$ during 5 hours in a muffle furnace and quenched in water. After that, the overaged samples underwent SEM, XRD, TEM and Vickers hardness test again. Then, overaged strips were cold-rolled from a thickness of $10 \mathrm{~mm}$ to $5.5 \mathrm{~mm}$ and 2.5 $\mathrm{mm}$ (thickness reductions of $45 \%$ and $75 \%$ ); c) The overaged and cold-rolled samples underwent isochronal and isothermal annealing heat treatments. Vickers hardness measurements from all annealed samples were obtained and the softening kinetics was studied by using these hardness data.

\section{Results and Discussion}

AA 7075 -T6 microstructure obtained by using PLM is presented in Figure 1. It is possible to notice elongated grains in the rolling direction. 
Table 1. Chemical composition (mass \%) of AA 7075 used in the present work.

\begin{tabular}{lcccccccccc}
\hline Component & $\mathrm{Ti}$ & $\mathrm{Mn}$ & $\mathrm{Si}$ & $\mathrm{Cr}$ & $\mathrm{Fe}$ & $\mathrm{Cu}$ & $\mathrm{Mg}$ & $\mathrm{Zn}$ & $\mathrm{Al}$ \\
\hline \% mass & 0.02 & 0.08 & 0.08 & 0.19 & 0.26 & 1.3 & 2.3 & 5.2 & 90.57 \\
\hline
\end{tabular}
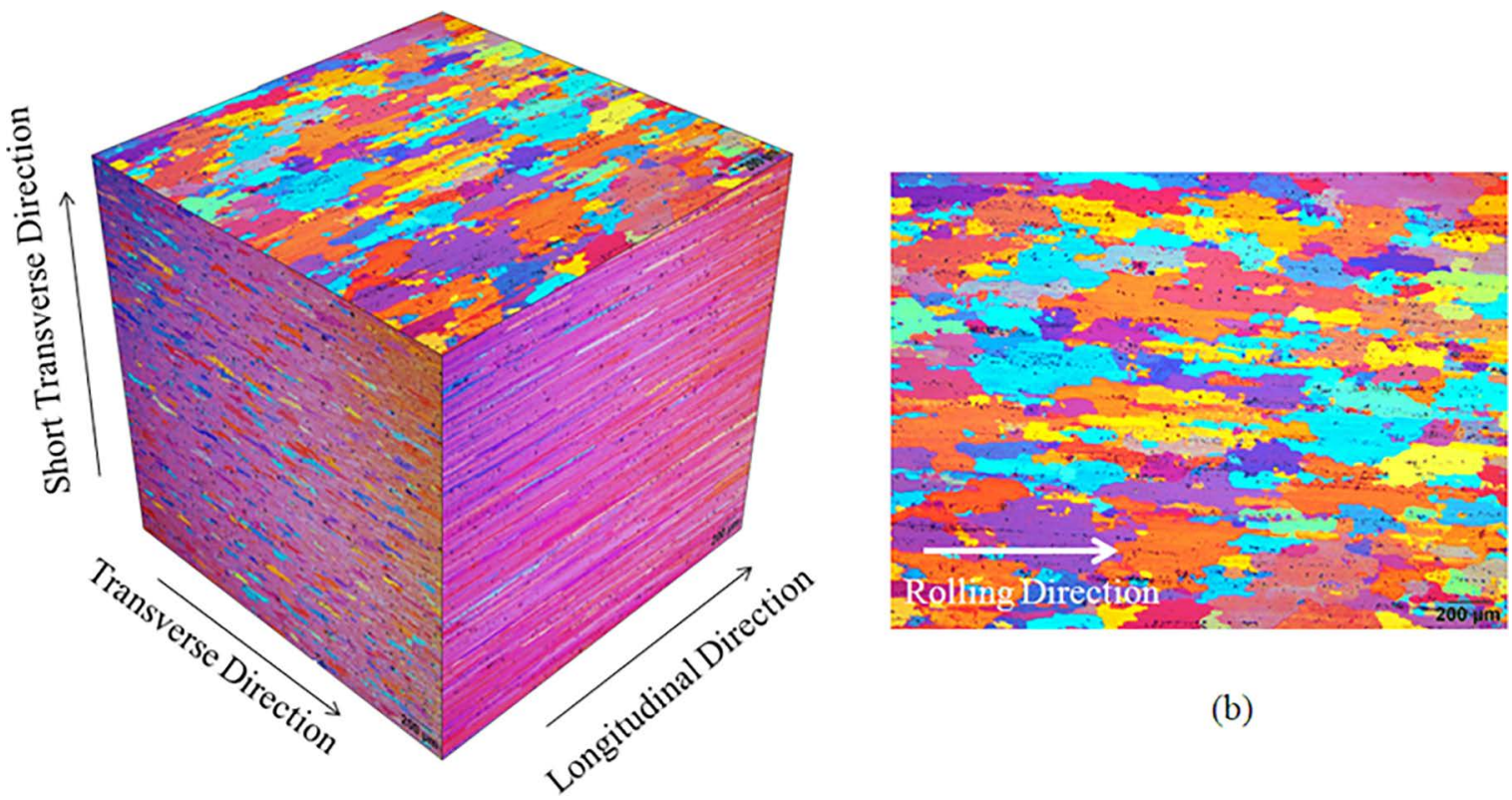

(a)

Figure 1. Microstructures of AA 7075 obtained by using polarized light microscopy. (a) views of three different planes and (b) a view of the rolling plane.

The grain boundaries show an undulated geometry. It may happen due to the high concentration of second phase precipitates that difficult the boundaries mobility during recrystallization process. The work of Martorano et al. calls those grain structures protrusions, and concludes that these undulations are caused due to a non -uniform strain energy distribution ${ }^{4}$. Similar grain structures are observed in other AA 7075 studies ${ }^{5,6}$.

Analyses made by SEM identified the presence of precipitates $(\sim 10 \mu \mathrm{m})$, aligned with the rolling direction. Figure 2 shows one of those precipitates and its EDS analysis results.

The observed particles contain, according to the EDS analysis, high contents of aluminum and copper, as well as magnesium and iron. It indicates that these precipitates are possibly a phase like $\mathrm{Al}_{2} \mathrm{MgCu}$ or $\mathrm{Al}_{7} \mathrm{Cu}_{2} \mathrm{Fe}$. The $\mathrm{Al}_{2} \mathrm{CuMg}$ phase was found by Cogan ${ }^{7}$ while an $\mathrm{AlCuMg}$ phase was reported in Wert's ${ }^{8}$ studies. These intermetallic particles are insoluble in $\mathrm{Al}$ matrix and do not have strong influence on softening during annealing (by recrystallization).

Conventional precipitation hardening (T6) leads to a fine and metastable dispersion of $\mathrm{MgZn}_{2}$ particles that cannot be seen at the magnification of the micrograph shown in
Figure 3. The observed particles are insoluble dispersoids formed by $\mathrm{Cr}$, as indicated by the high $\mathrm{Cr}$ content found via EDS analysis.

After the overaging heat treatment $\left(300^{\circ} \mathrm{C} / 5\right.$ hours $)$, small particles can be seen along grain boundaries, as shown in Figure 4.

Apparently, those particles are $\mathrm{MgZn}_{2}$ coarsened precipitates, since it is not possible to observe them in AA 7075 - T6 samples. An EDS analysis indicates that the particles shown in TEM micrograph of Figure 5 are $\mathrm{MgZn}_{2}$.

Figure 6 presents the microstructure obtained from polarized light microscopy of an overaged and cold-rolled ( $45 \%$ in thickness reduction) sample.

The grains of rolled samples are elongated along the rolling direction and their colors are not well defined as those in AA 7075 - T6 condition (compare it to Figure 1). The rolling step certainly changes the density and distribution of dislocations and leads to orientation changes inside grains, which result in the mixed color effect under polarized light ${ }^{9}$.

Table 2 presents Vickers hardness measurements of T6, overaged and cold-rolled (after overaging) samples.

T6 condition shows the highest hardness, since its microstructure is composed of nanometric $\mathrm{MgZn}_{2}$ particles, 


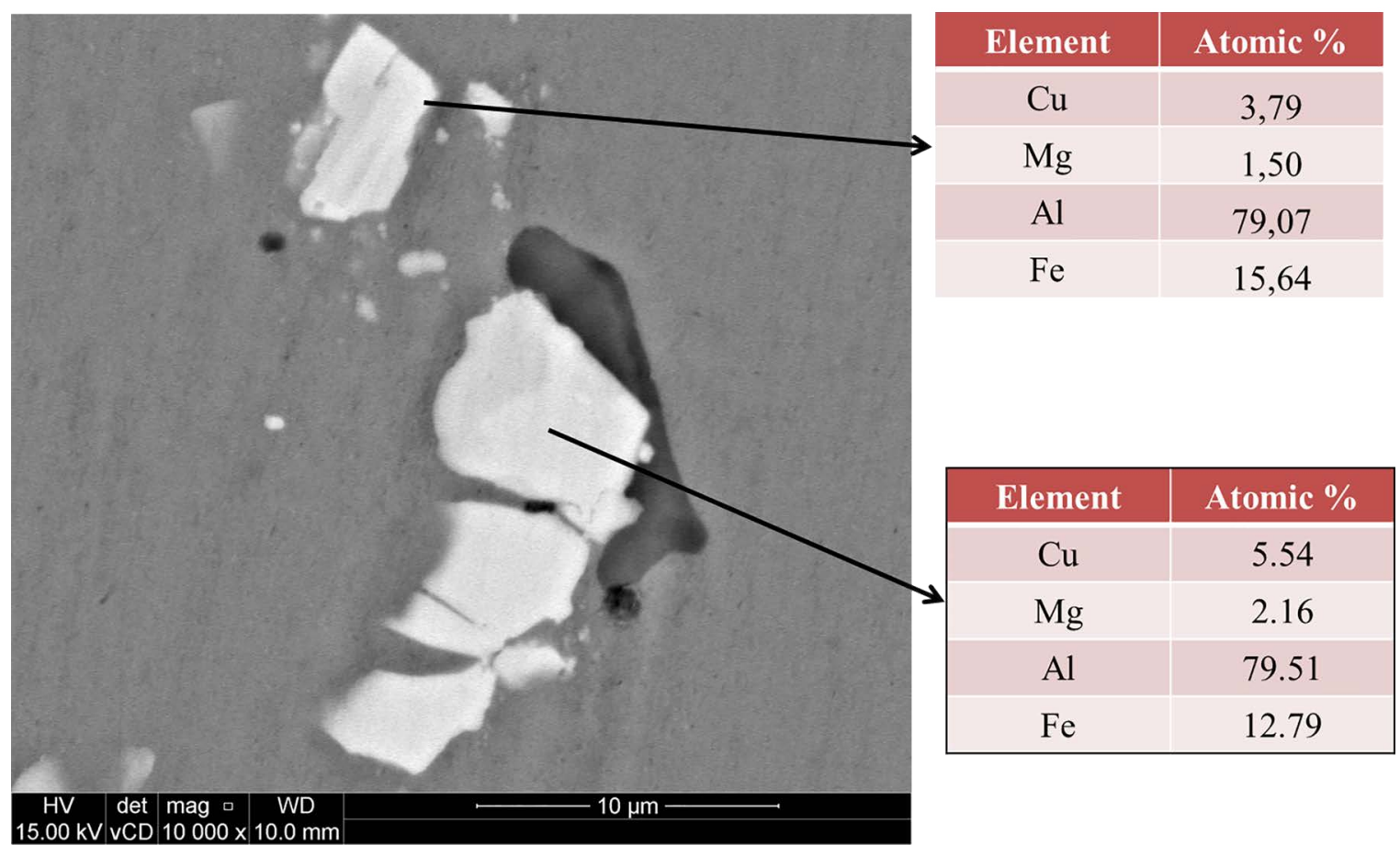

Figure 2. SEM image of observed particles.

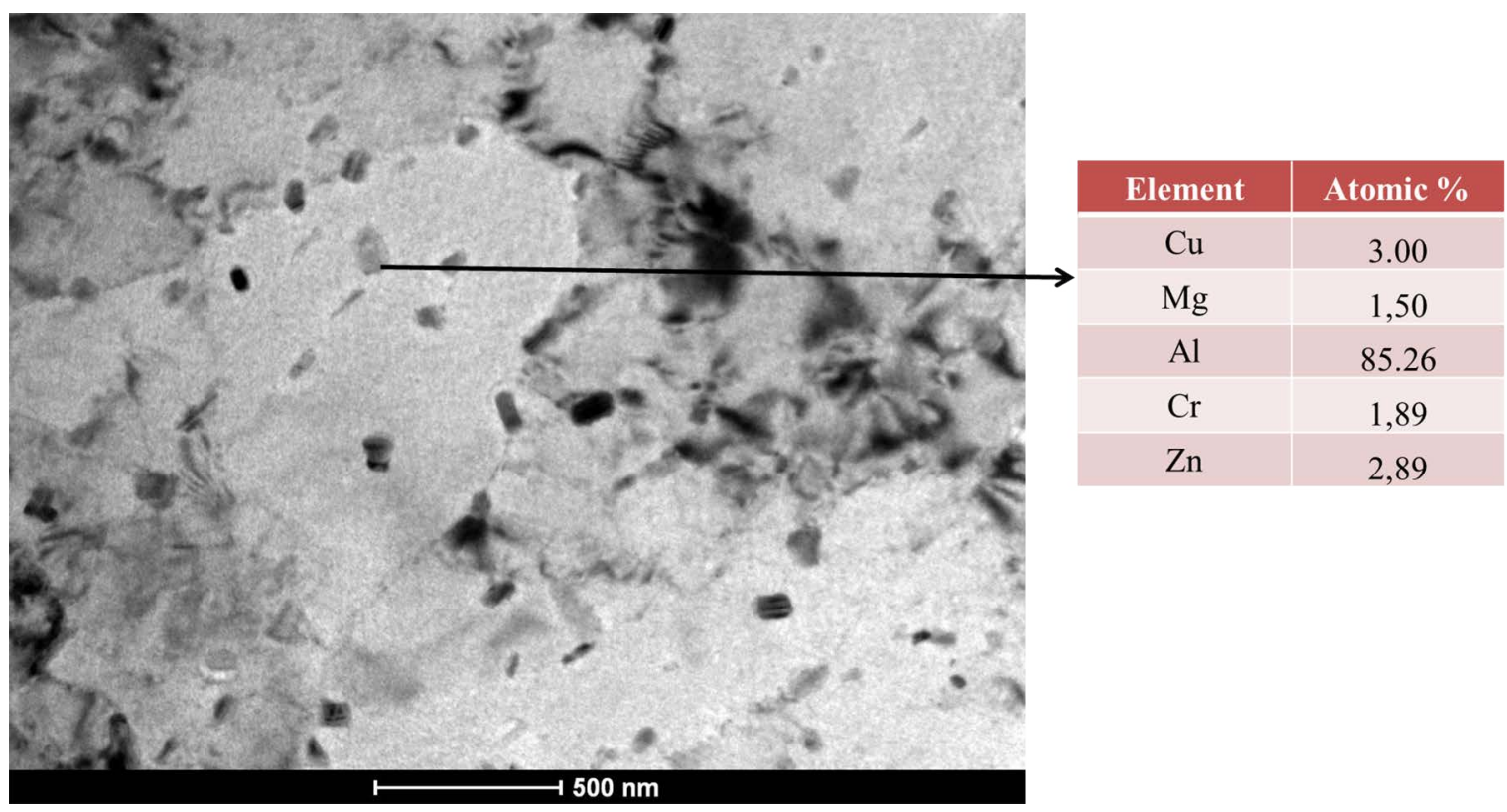

Figure 3. TEM micrograph of AA 7075 (T6). The observed particles are insoluble dispersoids and they are constituted of Cr.

which are responsible for making the dislocation motion difficult. As these particles grow during the overaging step, they lose their coherence with Al matrix and, therefore, lose efficiency in anchoring dislocation lines. Consequently, the hardness decreases.

As the material is cold-rolled, it becomes saturated with new dislocations, which increases hardness and the resistance to plastic deformation due to the interaction among these line defects.
After cold-rolling, the samples were annealed. Firstly, 4 hours isochronal heat treatments were carried out between 150 and $300^{\circ} \mathrm{C}$. Results are presented in Figure 7.

It is possible to notice that the hardness sharply decreases around $200^{\circ} \mathrm{C}$, while no significant changes occur for $150^{\circ} \mathrm{C}$. On the other hand, at $300^{\circ} \mathrm{C}$ the softening was relatively fast. This isochronal curve is relevant for planning the next isothermal heat treatments. 
Overaged and cold-rolled samples were submitted to two isothermal heat treatments at 200 and $250^{\circ} \mathrm{C}$. Results for both annealings are shown in Figure 8. After 4 hours, the sample treated at $250^{\circ} \mathrm{C}$ reaches the hardness level of overaged material $(81 \mathrm{HV})$, whilst samples heat treated at $200^{\circ} \mathrm{C}$ did not reach such softening degree (96 HV).

In order to identify the softening mechanisms, annealed samples were analyzed via EBSD. The results for the sample annealed at $250^{\circ} \mathrm{C}$ (4 hours) are shown in Figure 9. A large quantity of low-angle grain boundaries (red lines) may be seen inside regions delimited by high-angle grain boundaries (blue lines), probably the original grains (those existing before the samples were cold-rolled). It is also possible

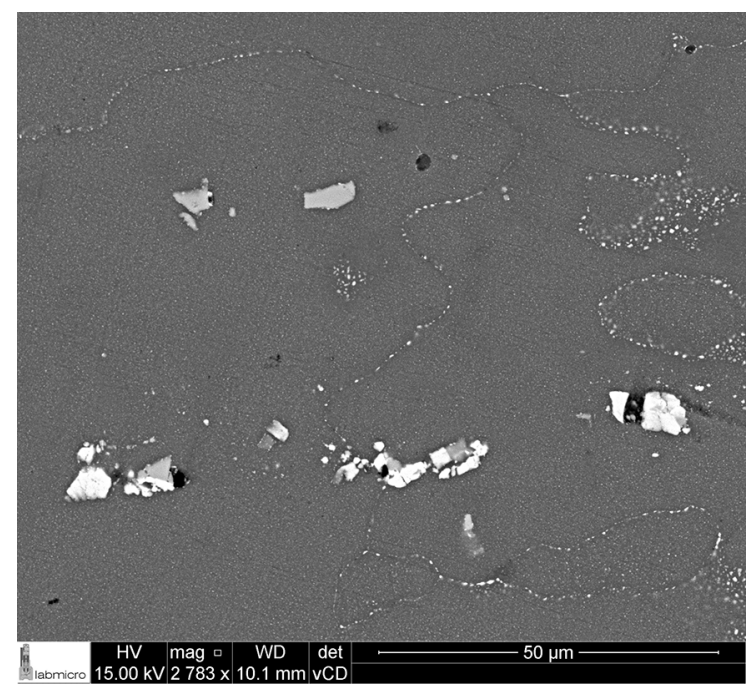

Figure 4. SEM image showing small particles of $\mathrm{MgZn}_{2}$ along matrix grain boundaries. to see few and small grains, probably new recrystallized grains. Since the volume fraction of recrystallized grains is smaller than $5 \%$, the decrease in hardness after annealing can be explained by intense recovery.

A model proposed by Kuhlmann ${ }^{10}$ to describe the recovery kinetics was used. This model states that the percentage

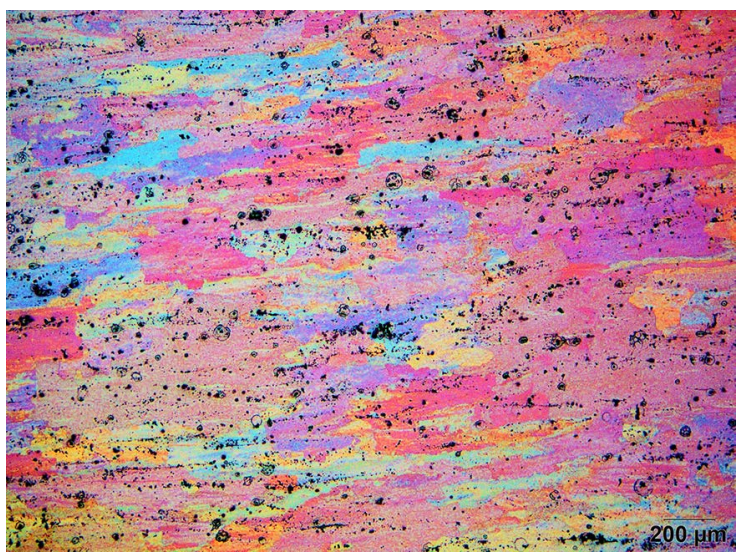

Figure 6. Microstructure of AA 7075 (rolling plane) after coldrolling obtained by using polarized light microscopy.

Table 2. Vickers hardness measures of AA 7075 at different conditions.

\begin{tabular}{lc}
\hline Themomechanical treatment & Vickers Hardness \\
\hline T6 (starting condition) & $180 \pm 8$ \\
Overaged $\left(300^{\circ} \mathrm{C}-5\right.$ hours) & $82 \pm 2$ \\
$\begin{array}{l}\text { Overaged and then cold-rolled } \\
(45 \%)\end{array}$ & $118 \pm 4$ \\
\hline
\end{tabular}

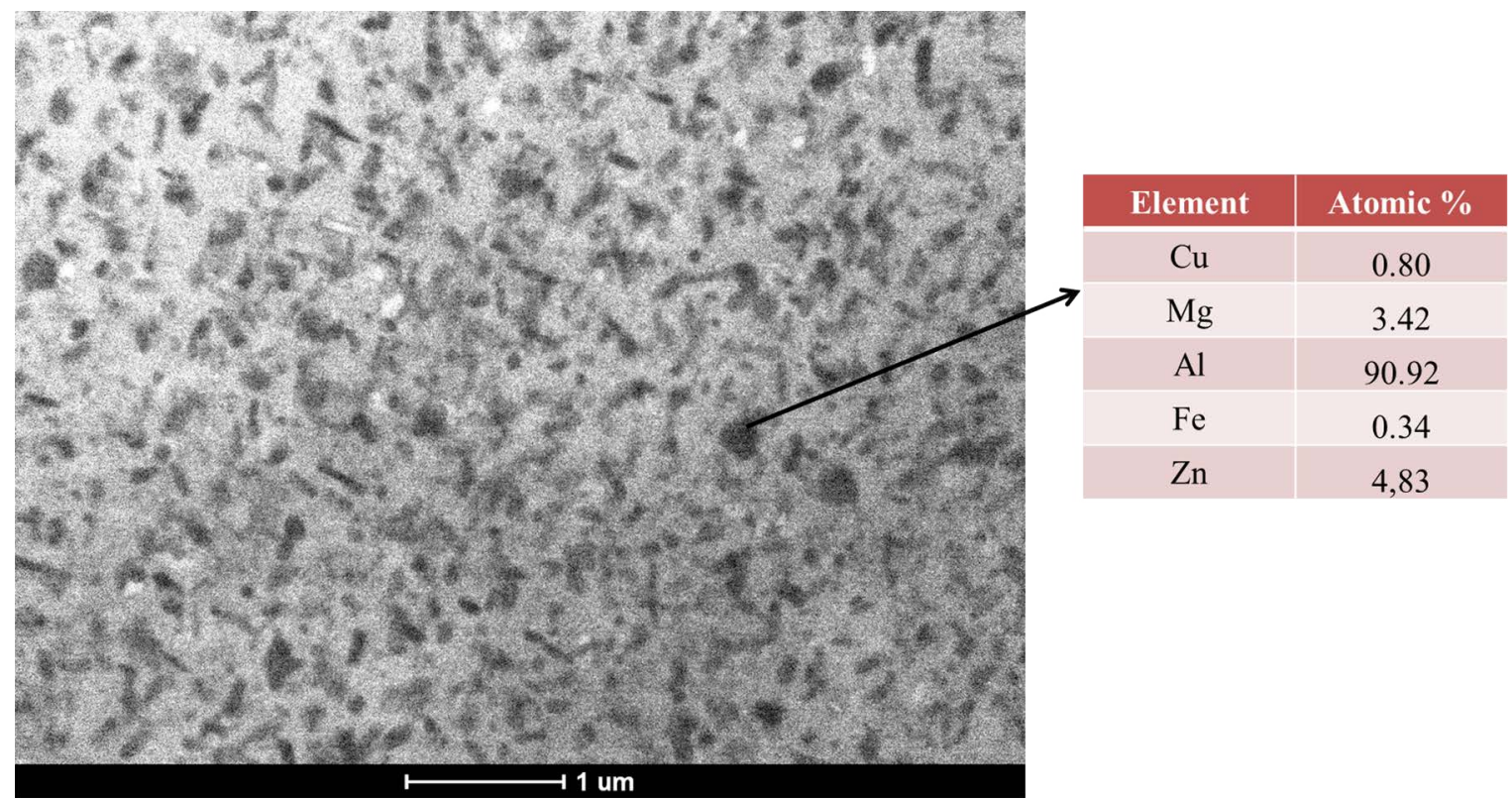

Figure 5. TEM micrograph showing $\mathrm{MgZn}_{2}$ coarsening and particles volume fraction increasing after AA 7075 overaging $\left(300^{\circ} \mathrm{C}\right.$ and 5 hours). 
recovery $(\mathrm{X})$ of deformed and annealed metallic materials can be expressed as:

$$
X=A-B \ln t
$$

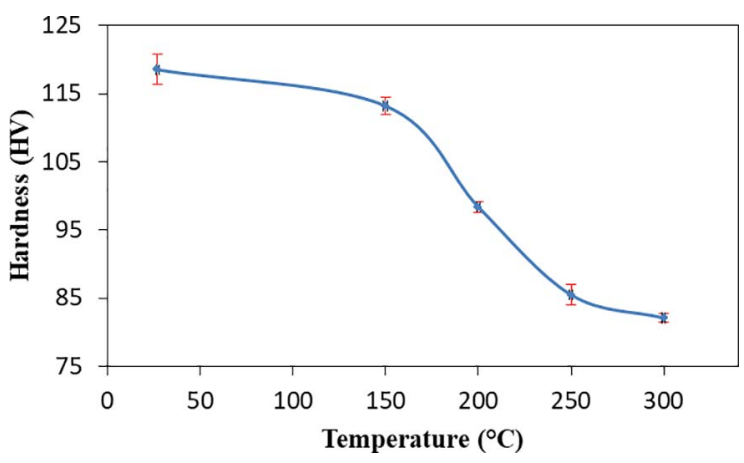

Figure 7. Softening behavior of cold - rolled (45\%) samples annealed for 4 hours at different temperatures

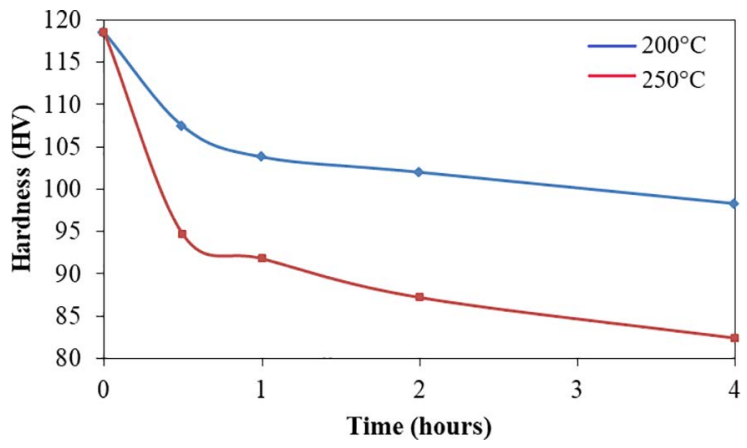

Figure 8. Softening behavior of samples annealed at $200^{\circ} \mathrm{C}$ and $250^{\circ} \mathrm{C}$.
Where "A" and " $\mathrm{B}$ " are constants to be determined and " $t$ " is the annealing time. The percentage of recovery can be estimated from hardness data according to:

$$
\% \text { Recovery }=\frac{H-H_{X}}{H-H_{R}}
$$

where $\mathrm{H}$ is alloy original hardness in the cold-rolled condition; $\mathrm{H}_{\mathrm{X}}$ is hardness after annealing under a specific condition and $H_{R}$ is hardness for a sample that has been fully recovered. The use of mechanical properties, such as hardness and tensile yield strength, to study microstructural changes has also been adopted by some authors. Tajally and Huda ${ }^{11}$ used a similar model to study the recrystallization kinetics for AA 7075. Sarkar ${ }^{12}$ found good correlation between mechanical properties (tensile yield strength) and quantitative metallography by applying a similar method in studies of AA 5754 recrystallization. Figure 10 illustrates the data fitting for both annealing temperatures, $200^{\circ} \mathrm{C}$ and $250^{\circ} \mathrm{C}$.

Alternatively, the results were fit to two other models, Austin-Rickett (AR) ${ }^{13}$ and Johnson-Mehl-Avrami-Kolmogorov (JMAK) ${ }^{14}$ Both models are traditionally used to describe phase transformations kinetics. The AR formula is expressed by:

$$
\log \left(\frac{f}{1-f}\right)=k \log (t)+C
$$

where " $\mathrm{f}$ " is transformed fraction, " $\mathrm{t}$ " is annealing time and " $\mathrm{k}$ " and " $\mathrm{C}$ " are constants to be determined experimentally. Figure 11 shows the results of AR data fitting for both $200^{\circ} \mathrm{C}$ and $250^{\circ} \mathrm{C}$.

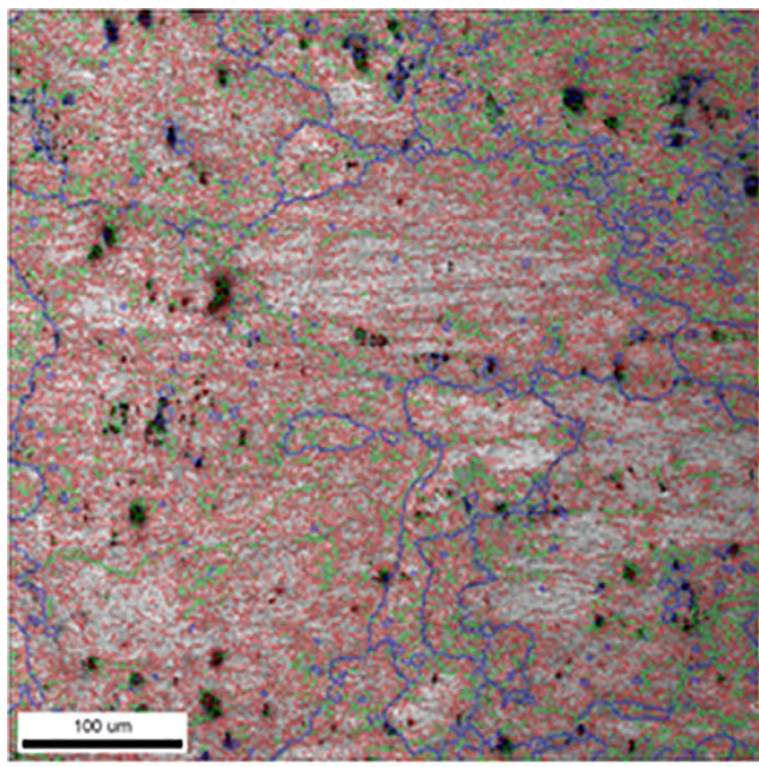

(a)

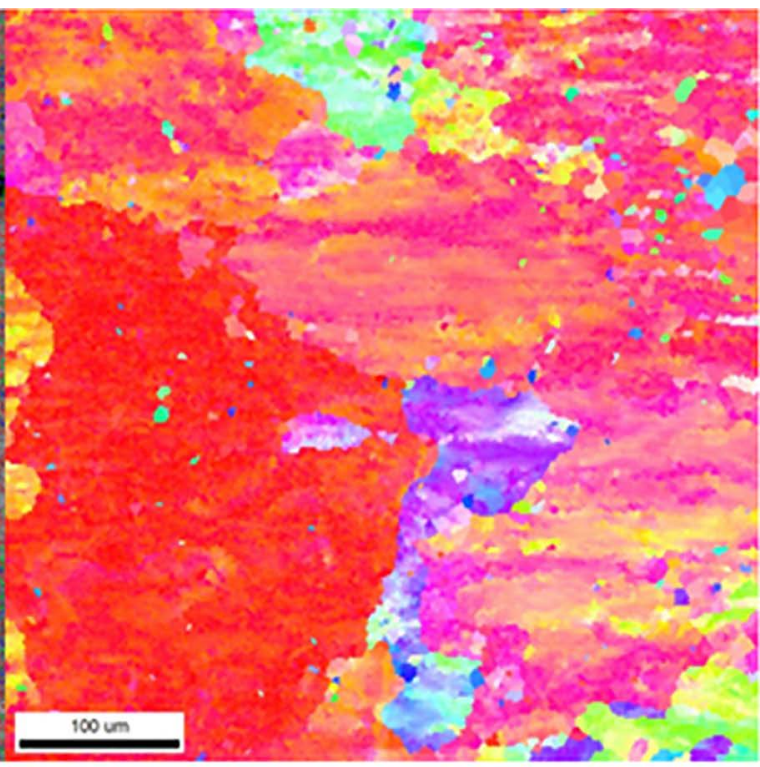

(b)

Figure 9. EBSD results for sample treated at $250^{\circ} \mathrm{C}$ for 4 hours. (a) Grain boundaries map. The red lines represent low-angle grain boundaries $\left(\theta<5^{\circ}\right)$, whilst green and blue lines represent medium $\left(5^{\circ}<\theta<15^{\circ}\right)$ and high $\left(\theta>15^{\circ}\right)$ angle grain boundaries, respectively). (b) EBSD map showing only few new recrystallized grains. 

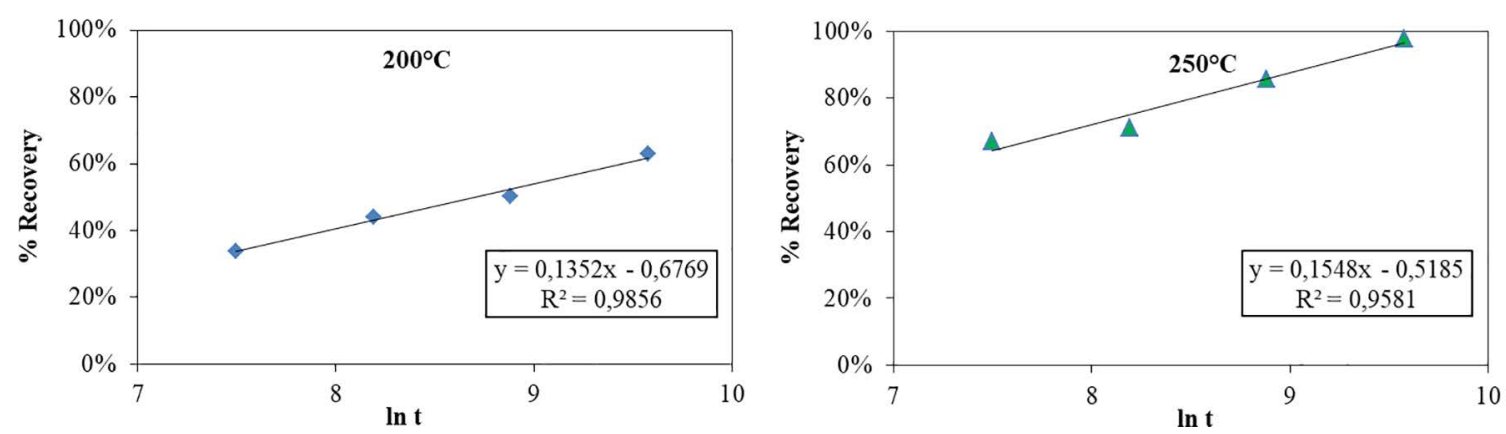

Figure 10. Variation of $\%$ Recovery with isothermal annealing time (t) at $200^{\circ} \mathrm{C}$ and $250^{\circ} \mathrm{C}$.
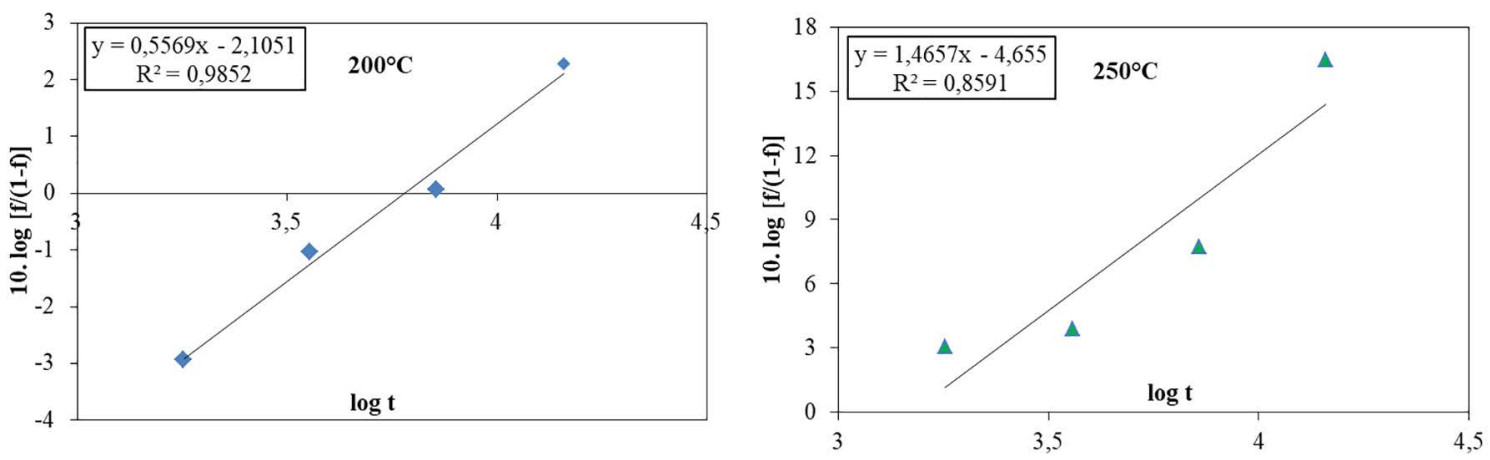

Figure 11. Austin-Riccket's data fitting of isothermal heat treatments at $200^{\circ} \mathrm{C}$ and $250^{\circ} \mathrm{C}$.

The JMAK relation can be expressed as:

$$
f=1-\exp \left(-D t^{n}\right)
$$

Where "f" is recrystallized grains' volume fraction, " $\mathrm{t}$ " is annealing time and " $\mathrm{B}$ " and " $\mathrm{n}$ " are constants to be determined experimentally. It is possible to express JMAK equation by using a traditional linear form:

$$
\ln \left[\ln \frac{1}{(1-f)}\right]=-\ln D+n \ln t
$$

Figure 12 presents the results JMAK plots (both linear and not linear form) for both annealing temperatures, $200^{\circ} \mathrm{C}$ and $250^{\circ} \mathrm{C}$.

Both equations fit well to experimental hardness data, although no evidences of recrystallization are found in any annealed sample. Regarding JMAK's and Austin-Rickett adjusts; they represent a really interesting, curious and unexpected outcome. Additional studies by using more annealing conditions may clarify why those models, based on nucleation and growth, have described recover kinetics so well. All adjustment data are summarized in Table 3.

It may be noticed that the best result (in terms of $\mathrm{R}^{2}$ ) is obtained when the model proposed by Kulhmann is used. Additionaly, it is also possible to realize that all models seem to work better at lower annealing temperatures.

In order to obtain recrystallized samples, a new condition of thickness reduction was used ( $75 \%$ in thickness reduction) for providing a higher level of strain energy and, consequently, a higher driving force for recrystallization. This time, an initial 1 hour isocronical annealing was performed. The results are shown in Figure 13. Again, there is a sharply decrease in hardness for temperatures between $150^{\circ} \mathrm{C}$ and $200^{\circ} \mathrm{C}$. Nevertheless, micrographs obtained by light polarized microscopy do not show new recrystallized grains for samples annealed within $150^{\circ} \mathrm{C}$ and $350^{\circ} \mathrm{C}$.

For $75 \%$ reduction of thickness, recrystallization phenomena is only observed for $400^{\circ} \mathrm{C}$ after 1 hour, as shown in Figure 14. For these annealing conditions, the microstructure is all composed of new equiaxed grains.

The temperature $\left(400^{\circ} \mathrm{C}\right)$ were kept, and three isothermal annealings were performed ( 8,15 and 30 minutes) by using overaged and cold-rolled (75\% in thickness reduction) samples. The micrographs for these annealed samples are shown in Figure 15. Samples annealed for 15 and 30 minutes are fully recrystallized, whilst the one annealed for 8 minutes seems to be only recovered. Apparently, recrystallization of samples which underwent $75 \%$ of thickness reduction takes place for time intervals between 8 and 15 minutes. It is very difficult, thus, to study recrystallization kinetics by using quantitative stereology methods, since the whole process takes place quickly.

The obtained results will be briefly summarized. AA 7075 at the starting condition (T6) has high hardness (180 HV) due to nanometric $\mathrm{MgZn}_{2}$ particles distributed in aluminum solid solution matrix. Since this alloy in as-supplied condition shows 

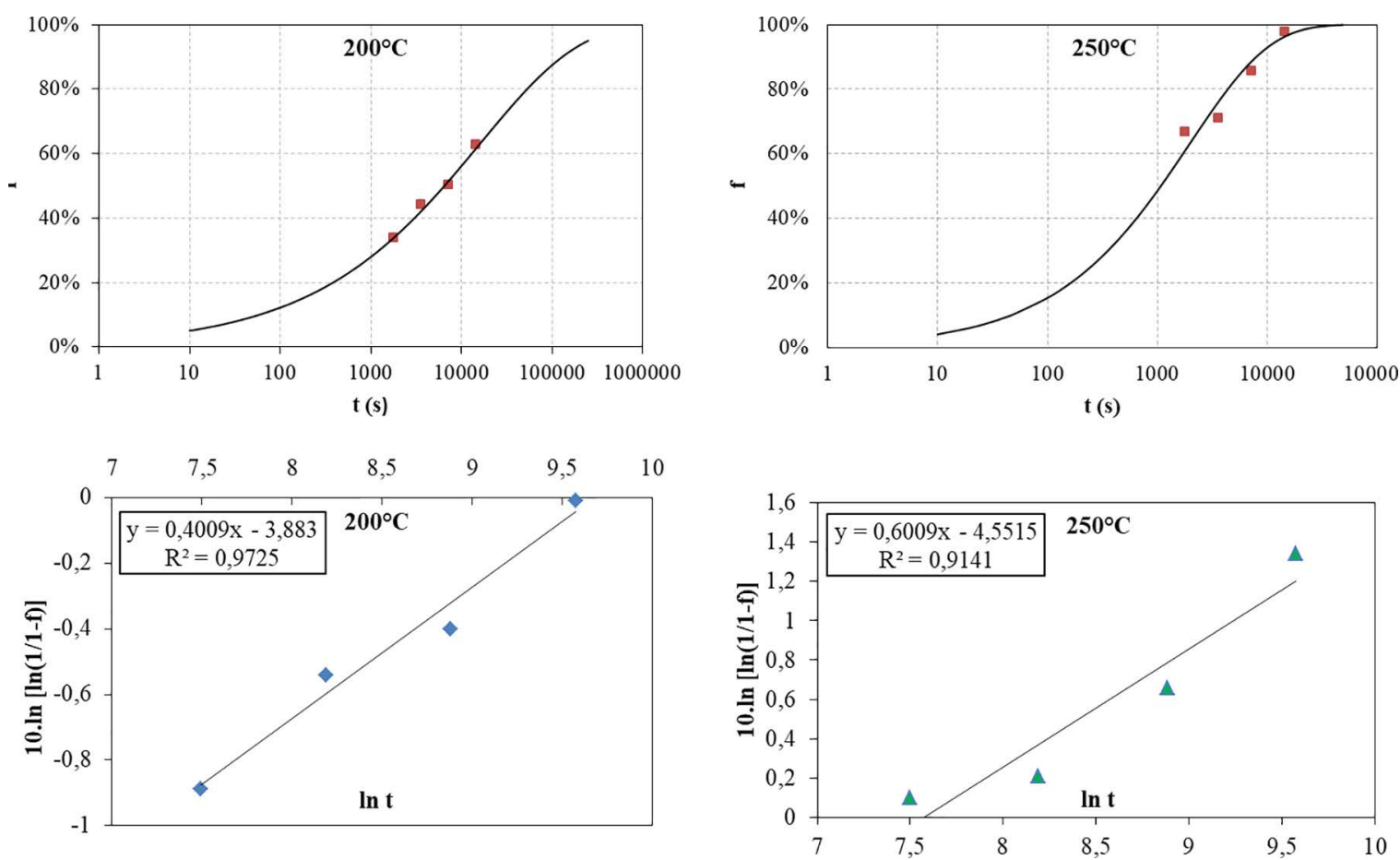

Figure 12. JMAK's exponential and linear data fitting of isothermal annealings at $200^{\circ} \mathrm{C}$ and $250^{\circ} \mathrm{C}$.

Table 3. Summarized results of all models used to adjust the experimental data

\begin{tabular}{lccc}
\hline Kulhmann & $\mathbf{A}$ & $\mathbf{B}$ & $\mathbf{R}^{\mathbf{2}}$ \\
$200^{\circ} \mathrm{C}$ & 0,677 & 0,135 & 0,9856 \\
$250^{\circ} \mathrm{C}$ & $-0,52$ & 0,155 & 0,9581 \\
\hline Austin - Riccket & $\mathbf{k}$ & $\mathbf{C}$ & $\mathbf{R}^{\mathbf{2}}$ \\
$200^{\circ} \mathrm{C}$ & 0,557 & $-2,105$ & 0,9852 \\
$250^{\circ} \mathrm{C}$ & 1,466 & $-4,655$ & 0,8591 \\
\hline $\mathbf{J M A K}$ & $\mathbf{n}$ & $\mathbf{D}$ & $\mathbf{R}^{\mathbf{2}}$ \\
$200^{\circ} \mathrm{C}$ & 0,4 & 0,021 & 0,9725 \\
$250^{\circ} \mathrm{C}$ & 0,6 & 0,011 & 0,9141 \\
\hline
\end{tabular}

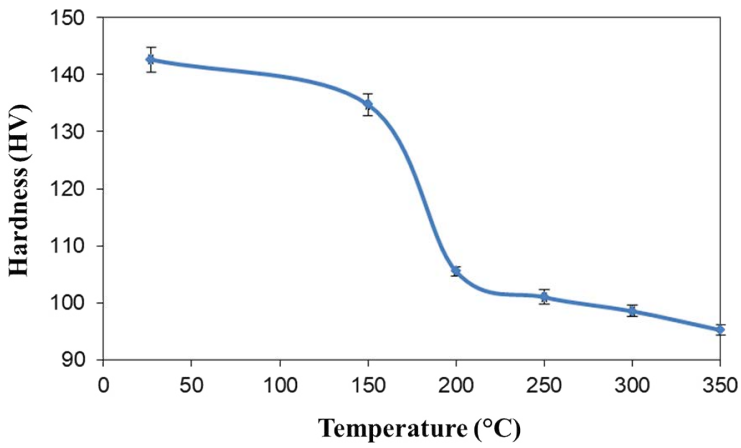

Figure 13. Softening behavior of cold-rolled (75\%) samples annealed for 1 hour at different temperatures.

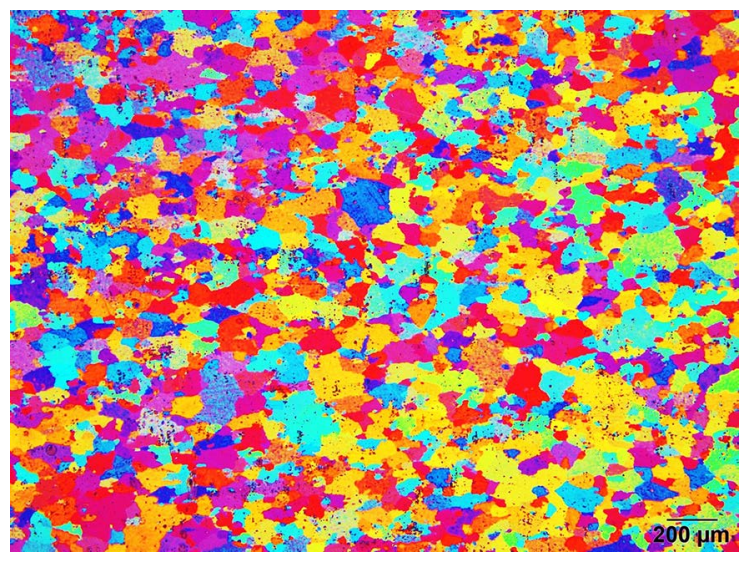

Figure 14. Microstructure of overaged AA 7075 after cold-rolling (75\% in thickness reduction) and annealing $\left(400^{\circ} \mathrm{C}\right.$ and 1 hour). Obtained by using polarized light microscopy.

low ductility, which makes cold-rolling in $\mathrm{T} 6$ condition very difficult, it was overaged at $300^{\circ} \mathrm{C}$ for 5 hours, resulting in coarsening of $\mathrm{MgZn}_{2}$ particles and, consequently, in hardness decreasing $\left(82 \mathrm{HV}\right.$ ). After overaging step, $\mathrm{MgZn}_{2}$ particles can be observed by transmission electron microscopy and also by scanning electron microscopy (Figures 4 and 5).

Cold-rolling induces dislocations arrays and changes the shape of grains, as shown in Figure 6. The Vickers hardness increases from $82 \mathrm{HV}$ to $118 \mathrm{HV}$ due to work hardening. 


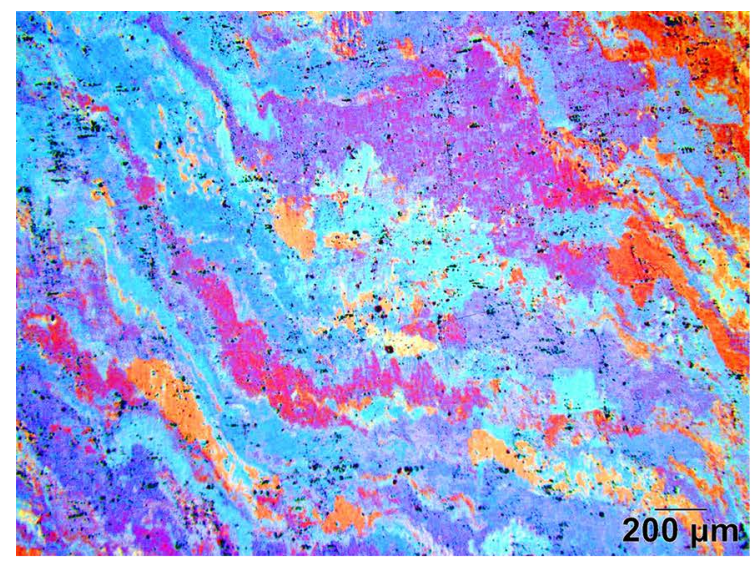

(a)

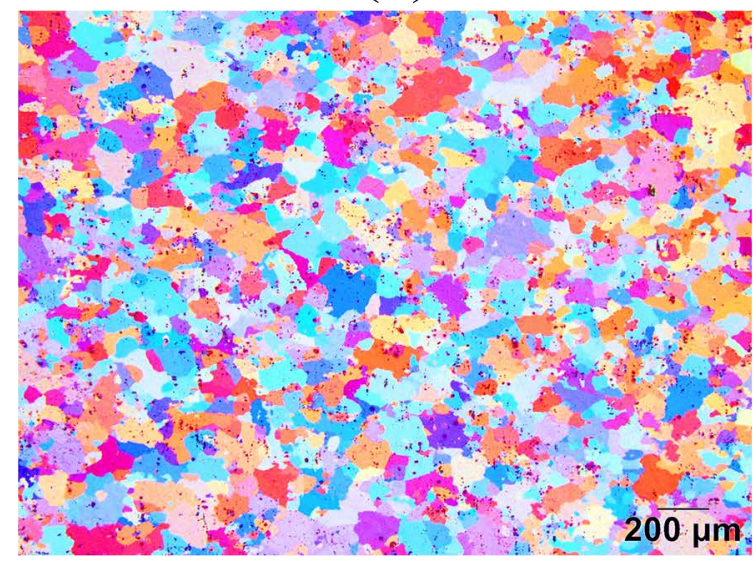

(c)

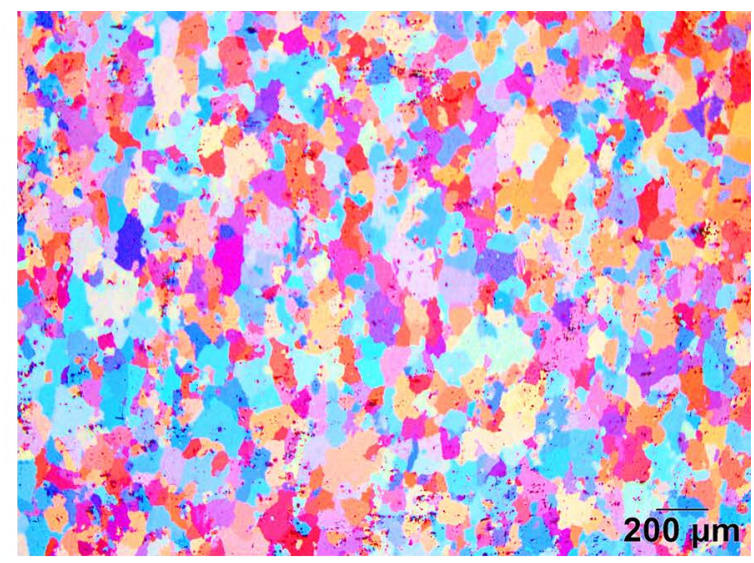

(b)

Figure 15. Microstructure of overaged AA 7075 after cold-rolling ( $75 \%$ in thickness reduction) and annealing $\left(400^{\circ} \mathrm{C}\right)$ for (a) 8 minutes, (b) 15 minutes and (c) 30 minutes. Obtained by using polarized light microscopy.

Subsequent annealing results in hardness decrease, as shown in Figures 7 and 8. Since no new recrystallized grains are found by optical microscopy and EBSD maps shows only a very low fraction of new recrystallized grains, the main contribution to the observed softening is attributed to recovery mechanisms. This assumption is confirmed when a classic model proposed by Kuhlmann to study recovery kinetics is applied. This model shows good agreement with experimental data (Figure 10). The good correlation to JMAK and AustinRickett (AR) models is unexpected, since these models are not proper for describing recovery kinetics.

By using a higher degree of thickness reduction (75\%), it is found that for 1 hour annealing, new recrystallized grains are not obtained until the temperature of $350^{\circ} \mathrm{C}$. For $400^{\circ} \mathrm{C}$ annealing, samples become fully recrystallized quickly (a time period between 8 and 15 minutes), difficulting thus the study of recrystallization kinetics.

\section{Conclusions}

1. Isothermal kinetics of softening can be described both by a classical equation (Kuhlmann equation) used for recovering kinetics and by two equations frequently used for nucleation and growth phase transformations such recrystallization (JMAK equation).

2. The degree of reduction of $45 \%$ is not enough to promote a significant recrystallized volume fraction for overaged samples of AA 7075, as it is possible to observe via optical microscopy using polarized light and by EBSD analysis. Therefore it is possible to state that, at least for the annealing temperatures used in this work, the critical strain for recrystallization is higher than $45 \%$ in thickness reduction. 
3. The model proposed by Kuhlmann ${ }^{10}$ (and frequently utilized to describe the recovery kinetics ${ }^{15}$ ) fits very well to hardness measurements. In this case, experimental data shows good correlation to the mathematical model, and almost all softening can be attributed to recovery mechanisms. Unexpectedly, JMAK and AR models also fit the experimental data well.

4. The use of $75 \%$ of reduction is not enough to promote recrystallization for annealing temperatures between 150 and $350^{\circ} \mathrm{C}(1$ hour $)$. By using $400^{\circ} \mathrm{C}$ it is possible to achieve a microstructure composed of recrystallized grains for different annealing times. A fully recrystallized microstructure for overaged and $75 \%$ cold-rolled samples is achieved (at $400^{\circ} \mathrm{C}$ ) in a period of time between 8 and 15 minutes.

Although it was not possible to enhance the material mechanical properties, the present study has achieved interesting results about recovering kinetics and also a grain refinement route. It was found that mathematical models used to quantify recrystallization kinetics can (at least for this specific situation) describe recovery kinetics fairly well.

Future works may aim in achieving mechanical properties enhance by using, for instance, a combination of work hardening and precipitation in 7XXX aluminum alloys (in this case, the main idea is to solubilize, strain and carry out aging treatments at temperatures that are low enough for not causing recrystallization.

\section{Acknowledgements}

The authors thanks CAPES for the financial support to one of the authors (SHS), CBA and its employees (Miguel Borodiak and Alexandro Rafael de Andrade) for their help with samples preparation for polarized light microscopy and Professor Marcelo de Aquino Martorano (EPUSP) for revising the English text of the manuscript. This study was financed in part by the Coordenação de Aperfeiçoamento de Pessoal de Nível Superior - Brasil (CAPES) - Finance Code 001.

\section{References}

1. El-Baradie ZM, El-Sayed M. Effect of double thermomechanical treatments on the properties of $7075 \mathrm{Al}$ alloy. Journal of Materials Processing Technology. 1996;62(1-3):76-80.
2. Huo WT, Shi JT, Hou LG, Zhang JS. An improved thermomechanical treatment of high-strength $\mathrm{Al}-\mathrm{Zn}-\mathrm{Mg}-\mathrm{Cu}$ alloy for effective grain refinement and ductility modification. Journal of Materials Processing Technology. 2017;239:303-314.

3. Wert JA, Paton NE, Hamilton CH, Mahoney MW. Grain refinement in 7075 aluminum by thermomechanical processing. Metallurgical Transactions A. 1981;12(7):1267-1276.

4. Martorano MA, Fortes MA, Padilha AF. The growth of protrusions at the boundary of a recrystallized grain. Acta Materialia. 2006;54(10):2769-2776.

5. Goloborodko A, Ito T, Yun X, Motohashi Y, Ioth G. Friction Stir Welding of a Commercial 7075-T6 Aluminum Alloy: Grain Refinement, Thermal Stability and Tensile Properties. Materials Transactions. 2004;45(8):2503-2508.

6. Guimarães PB, Oliveira CAN, da Silva RJF, Yadava YP, Ferreira RAS. A Cinética de Recristalização da Liga de Alumínio AA 8023. Revista Eletrônica de Materiais e Processos. 2011;6(3):188-193.

7. Cogan SF, Gayle FW, Klein JD, Cocks FH, Shepard ML. Extraction and X-ray analysis of phases in aluminium alloys. Journal of Materials Science. 1978;13(12):2687-2691.

8. Wert JA. Identification of precipitates in $7075 \mathrm{Al}$ after hightemperature aging. Scripta Metallurgica. 1981;15(4):445-447.

9. Slámová M, Očenášek V, Vander Voort G. Polarized light microscopy: utilization in the investigation of the recrystallization of aluminum alloys. Materiais Characterization. 2004;52(3):165177.

10. Kuhlmann D. Zur Theorie der Nachwirkungserscheinungen. Zeitschrift für Physik. 1948;124(7-12):469-481.

11. Tajally M, Huda Z. Recrystallization kinetics for aluminum alloy 7075. Metal Science and Heat Treatment. 2011;53(56):213-217.

12. Sarkar S, Wells MA, Poole WJ. Softening behaviour of cold rolled continuous cast and ingot cast aluminum alloy AA5754. Materials Science and Engineering: A 2006;421(1-2):276-285.

13. Austin JB, Rickett RL. Kinetics of the Decomposition of Austenite at Constant Temperature. Transactions of the American Institute of Mining and Metallurgical Engineers. 1939;135:396-415.

14. Johnson WA, Mehl RF. Reaction Kinetics in Process of Nucleation And Growth. Transactions of the American Institute of Mining and Metallurgical Engineers. 1939;135:416-442.

15. Humphreys FJ, Hatherly M. Recrystallization and Related Annealing Phenomena. Oxford: Elsevier; 2004. 